BMJ Open Diabetes Research \& Care

\title{
Dilated eye examination screening guideline compliance among patients with diabetes without a diabetic retinopathy diagnosis: the role of geographic access
}

\author{
David J Lee, ${ }^{1}$ Naresh Kumar, ${ }^{1}$ William J Feuer, ${ }^{2}$ Chiu-Fang Chou, ${ }^{3}$ Potyra R Rosa, ${ }^{2}$ \\ Joyce C Schiffman, ${ }^{2}$ Alexis Morante, ${ }^{2}$ Adam Aldahan, ${ }^{2}$ Patrick Staropoli, ${ }^{2}$ \\ Cristina A Fernandez, ${ }^{1}$ Stacey L Tannenbaum, ${ }^{1}$ Byron L Lam ${ }^{2}$
}

To cite: Lee DJ, Kumar N, Feuer WJ, et al. Dilated eye examination screening guideline compliance among patients with diabetes without a diabetic retinopathy diagnosis: the role of geographic access. BMJ Open Diabetes Research and Care 2014;2:e000031. doi:10.1136/bmjdrc-2014000031

Results of this study have been presented previously as an abstract at the annual conference of the Association for Research in Vision and Ophthalmology, Seattle, Washington, USA May 2013.

Received 26 March 2014 Revised 11 July 2014 Accepted 3 August 2014

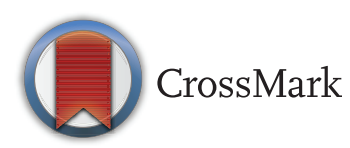

For numbered affiliations see end of article.

Correspondence to Dr David J Lee;

DLee@med.miami.edu

\section{ABSTRACT}

Objective: To estimate the prevalence of, and factors associated with, dilated eye examination guideline compliance among patients with diabetes mellitus (DM), but without diabetic retinopathy.

Research design and methods: Utilizing the computerized billing records database, we identified patients with International Classification of Diseases (ICD)-9 diagnoses of DM, but without any ocular diagnoses. The available medical records of patients in 2007-2008 were reviewed for demographic and ocular information, including visits through $2010(\mathrm{n}=200)$. Patients were considered guideline compliant if they returned at least every 15 months for screening. Participant street addresses were assigned latitude and longitude coordinates to assess their neighborhood socioeconomic status (using the 2000 US census data), distance to the screening facility, and public transportation access. Patients not compliant, based on the medical record review, were contacted by phone or mail and asked to complete a follow-up survey to determine if screening took place at other locations.

Results: The overall screening compliance rate was $31 \%$. Patient sociodemographic characteristics, insurance status, and neighborhood socioeconomic measures were not significantly associated with compliance. However, in separate multivariable logistic regression models, those living eight or more miles from the screening facility were significantly less likely to be compliant relative to those living within eight miles (OR=0.36 (95\% Cl 0.14 to 0.86$)$ ), while public transit access quality was positively associated with screening compliance (1.34 (1.07 to 1.68)).

Conclusions: Less than one-third of patients returned for diabetic retinopathy screening at least every 15 months, with transportation challenges associated with noncompliance. Our results suggest that reducing transportation barriers or utilizing community-based screening strategies may improve compliance.

The number of American adults 20 years of age and older living with diabetes mellitus

\section{Key messages}

- Dilated eye examination guideline compliance among patients with diabetes mellitus is low.

- Quality of access to public transportation was positively correlated with screening compliance.

- Transportation assistance interventions and more comprehensive community-based screening models need to be developed and tested.

(DM) has increased by approximately $75 \%$ over the past two decades, with the largest absolute increases in prevalence occurring in those 65 years of age and older. ${ }^{1}$ Symptoms of the early stages of DM are frequently missed; in 2010, there were an estimated seven million Americans of all ages living with undiagnosed diabetes. ${ }^{2}$ Diabetic retinopathy is a complication of DM; the risk of diabetic retinopathy increases with the number of years of living with this condition. ${ }^{3}$ Diabetes treatment is complex and poor management is a major risk factor for the development of retinopathy. ${ }^{3}$ Diabetic retinopathy is the leading cause of blindness in US adults over the age of 40 despite the availability of effective treatment. ${ }^{3}{ }^{4}$ By 2050 , the number of Americans aged 40 years or older and living with DM is expected to triple to 16 million, with over 3 million having advanced vision-threatening disease. ${ }^{5}$

Early detection of diabetic retinopathy is critical, given that prompt treatment increases the likelihood of preserving vision. ${ }^{3}$ Unfortunately, many adults living with DM remain unaware of their ocular condition until their diabetic retinopathy has progressed to a stage at which treatment is difficult. $^{6}$ The American Academy of 
Ophthalmology, to encourage early detection of diabetic retinopathy, endorses annual dilated eye examinations for patients with type 1 and 2 diabetes. ${ }^{7}$ Additionally, the American Diabetes Association recommends annual dilated eye examinations after diagnosis of DM, although the guidelines leave some flexibility for less frequent ocular examinations by ophthalmologists or optometrists in the presence of one or more normal eye examination results. ${ }^{8}$

Unfortunately, not everyone who should do so receives annual dilated eye examinations. Factors which influence screening compliance include lack of insurance and healthcare access, knowledge of diabetes-specific ocular risk, and health literacy, cultural, and language barriers. ${ }^{9-12}$ An analysis of Medicare claims data found that slightly more than $50 \%$ of patients with newly diagnosed DM had at least one 15-month gap between eye examinations during the first 30 months of living with this condition. ${ }^{13}$ Among enrollees of an independent practice association, only $16 \%$ of those with diabetes underwent annual eye examination in two consecutive years. ${ }^{14}$ Yearly reminders to those enrolled in one large managed care organization yielded only a $28 \%$ 1-year reexamination rate. ${ }^{15}$

While it is important to evaluate adherence for all persons with diabetes, regardless of whether retinopathy has already been diagnosed, there is scant literature about screening adherence in persons with diabetes who do not have a retinopathy diagnosis. We identified factors associated with compliance for annual dilated eye examination guidelines among patients with diagnosed DM, but without diabetic retinopathy. Given that geographic access to healthcare and screening facilities is critically important for compliance, poor access (such as longer traveling time, high transportation cost, and burdensome public transportation options) can be a potent barrier. ${ }^{16-18}$ However, to the best of our knowledge, no study has examined the association between compliance and ease of access to screening sites via public transportation. Here, we examine how compliance was associated with patient-level factors, as well as distance from the screening facility and transit score, a measure of access to public transport facilities.

\section{RESEARCH DESIGN AND METHODS}

\section{Medical record identification and review}

Utilizing computerized billing records, we selected the Bascom Palmer Eye Institute patients initially seen with International Classification of Disease (ICD)-9 diagnoses of DM (types 1 and 2) without diabetic complications and without diabetic retinopathy or any other eye disease. Since we were interested in examining transit-related compliance factors, we further restricted our sample to patients who resided within the same county as the screening facility (ie, Miami-Dade County). The sample of available and eligible patient records first seen in 2007-2008 (n=203) was reviewed for demographic information (eg, age, sex, and race/ethnicity) at the screening visit, and all clinic visits through 2010 were ascertained by chart review. Insurance status was obtained from medical billing records based on current information available as of June 2, 2011. On review, three patients had diabetic retinopathy diagnoses recorded in their medical record and were eliminated, resulting in a final sample size of 200 patients.

\section{Diabetic retinopathy screening compliance}

Although compliance guidelines for dilated eye examinations specify annual visits, we defined compliance in our sample as returning at least every 15 months (coded as $0=$ noncompliant, $1=$ complaint). We chose 15 months to account for annual scheduling variations, such as patient/provider-requested scheduling issues or being away from the area as a consequence of travel or other reasons. $^{13}$

\section{Participant follow-up}

To determine if they received care at a location other than the Bascom Palmer Eye Institute, we attempted to call those patients whose medical records indicated that they were not guideline compliant. A minimum of five attempts were made. Patients who were unreachable by telephone were mailed a questionnaire sent to their last known address. A total of 45 and 8 patients, respectively, completed the telephone interviews or returned the mailed questionnaires.

\section{Census data abstraction}

Each participant's last known address was geocoded to abstract sociodemographic neighborhood characteristics using publicly available block and tract-level data from the 2000 US Census. While demographic data (such as race/ethnicity and household information) were available at the block level, economic data were only available at the census tract level. Generally, a block is small in area; for example, a block in a city is bounded on all sides by streets. Blocks are nested within block groups and block groups within census tracts. The population size of a census tract ranges from 1200 to 4000 people. ${ }^{19}$ Abstracted data fields included: the average age of the head of the household, the number of people with white race designation, the percent of households with married couples, the median household income, the percent of families receiving public assistance, the median real estate taxes, and the percent of owner occupied households.

\section{Transit score variable creation}

Bascom Palmer Eye Institute, the eye care facility, is located near downtown Miami, which is connected to most public transport facilities (metro rail and bus services). We first calculated the Euclidean distance (in miles) between the eye care facility and residential locations of participants. This point-to-point calculation is a crude indicator of the level of geographic access to the 
eye care facility since it does not take into account roadway patterns and the availability of public transportation to the site. We therefore extracted data from the Walk Score website using web-mining techniques (http://www.walkscore.com/) ${ }^{20}$ Walk Score values range between 0 and 100. A transit score of $0-24$ is coded as 'minimal transit' and $90-100$ is coded as 'Rider's paradise'. We sent five random locations within half a mile of each participant's residence to the Walk Score and acquired transit score estimates for each of the five locations. We then computed the average of these five scores, assigning for each the average transit score to each respective participant. We had two major categories of Walk Score values: minimal transit and all others. Since places with minimal transit options have similar characteristics (poor access to public transport facilities) and the rest of the places increment quantitatively with the increase in transit facilities, we converted the Walk Score to an ordinal scale by assigning 1 to all Walk Scores $<20$, and by dividing the rest by 10 . The resulting scale then ranged from 1 to 10 .

\section{Statistical analyses}

Comparisons of patient-level factors and US censusderived estimates of neighborhood sociodemographic status as a function of compliance status were made at the univariate level using the IBM/SPSS statistical package (IBM SPSS Statistics V.21). The means of age and socioeconomic variables in compliant versus noncompliant participants were compared using analysis of variance. The statistical significance of associations between sex, race/ethnicity, and health insurance status was assessed with the $\chi^{2}$ test.

Logistic regression modeling was employed to examine the association between transit scores and select individual-based and area-based measures with adjustment for the spatial trend using the logit function with a robust SE option in Stata (STATA/SE V.10.1). We first undertook multivariable analyses to determine if the Euclidean distance between the eye care facility and the patients' home was associated with compliance. In this analysis, we partitioned distance using the average distance into two categories: less than the average distance coded as 0 , and the rest coded as $1 \quad(<8$ vs $\geq 8$ miles). In separate logistic regression modeling, we examined the association between transit score and compliance. Given that there was evidence of spatial trends in these data (ie, presence of similarities in geographic distribution of compliance and noncompliance), a distance-weighted autocovariate was generated in $\mathrm{R}$ using the spdep library which was included as a covariate in the regression models. ${ }^{21} 22$

For both sets of analyses, we employed a stepwise approach to demonstrate how compliance varies with transit scores with and without the control for individualbased and area-based measures and spatial trend. We first modeled the association of transit score with compliance independent of any other variables (model 1), followed by a model which controlled for spatial autocorrelation (model 2). The next model included spatial autocorrelation and patient-level factors including age, sex, and insurance status (model 3). The final model included these variables along with two representative census-based neighborhood sociodemographic indicators, namely the percentage of neighborhood white race designation and median household income. Results were considered significant if $\mathrm{p}<0.05$.

\section{RESULTS}

Characteristics of the study population are provided in table 1. Patients averaged 51 years of age with slightly more women than men (53\%). The sample was diverse with respect to race/ethnicity with $43 \%$ Hispanic, and $23 \%$ reporting their race as African-American, non-Hispanic. Nearly half $(46 \%)$ had public insurance (eg, Medicaid and Medicare) with another $44 \%$ reporting being privately insured. The median neighborhood household income was slightly less than $\$ 35000$, which was below the median amount of $\$ 39425$ for all residents of Miami-Dade County in the year 2000. However, the percentage of patients living in neighborhoods with families receiving public assistance was low $(7.4 \%)$, and was slightly higher than the percentage for the entire county $(6.8 \%)$.

Incorporating results from the telephone and mailing outreach efforts yielded an estimated compliance rate of $31 \%(62 / 200)$. Of the 200 patients, $12.5 \% \quad(n=25)$ were judged to be guideline compliant based on a medical

Table 1 Sociodemographic characteristics of the study sample $(\mathrm{N}=200)$

\begin{tabular}{|c|c|c|c|}
\hline Characteristic & $\mathbf{n}$ & $\begin{array}{l}\text { Mean/ } \\
\text { per cent }\end{array}$ & SE \\
\hline \multicolumn{4}{|l|}{ Individual level } \\
\hline Screening age & 198 & 50.9 & 1.2 \\
\hline Female & 107 & $53.5 \%$ & \\
\hline \multicolumn{4}{|l|}{ Race-ethnicity } \\
\hline Black, non-Hispanic & 45 & $22.5 \%$ & \\
\hline White, non-Hispanic & 35 & $17.5 \%$ & \\
\hline Hispanic & 86 & $43.0 \%$ & \\
\hline Other/unknown & 34 & $17.0 \%$ & \\
\hline \multicolumn{4}{|l|}{ Insurance status } \\
\hline Uninsured (self-pay) & 18 & $9.8 \%$ & \\
\hline Public insurance & 85 & $46.4 \%$ & \\
\hline Private insurance & 80 & $43.7 \%$ & \\
\hline \multicolumn{4}{|l|}{ Area-based characteristics } \\
\hline Average household age (years) & 195 & 38.5 & 9.4 \\
\hline Percentage of white population & 195 & 62.1 & 2.1 \\
\hline Percentage of married couples & 195 & 64.1 & 0.8 \\
\hline Median household income (\$) & 195 & 34984 & 780 \\
\hline $\begin{array}{l}\text { Percentage of families receiving } \\
\text { public assistance }\end{array}$ & 195 & 7.4 & 0.3 \\
\hline Median real estate taxes (\$) & 195 & 1828 & 62 \\
\hline $\begin{array}{l}\text { Percentage of owner occupied } \\
\text { houses }\end{array}$ & 195 & 56.3 & 1.2 \\
\hline
\end{tabular}


Table 2 Sociodemographic characteristics among study participants compliant and noncompliant with screening guidelines

\begin{tabular}{|c|c|c|c|c|c|}
\hline \multirow[b]{2}{*}{ Characteristic } & \multicolumn{2}{|c|}{$\begin{array}{l}\text { Not fully compliant } \\
(n=138)\end{array}$} & \multicolumn{2}{|c|}{ Fully compliant $(n=62)$} & \multirow[b]{2}{*}{ p Value } \\
\hline & Mean/per cent & SE & Mean/per cent & SE & \\
\hline \multicolumn{6}{|l|}{ Individual level } \\
\hline Age & 52.0 & 1.4 & 48.4 & 2.4 & 0.17 \\
\hline Sex & & & & & 1.00 \\
\hline Male $(n=92)$ & $68.5 \%$ & & $31.5 \%$ & & \\
\hline Female $(n=107)$ & $69.2 \%$ & & $30.8 \%$ & & \\
\hline Race-ethnicity & & & & & 0.47 \\
\hline Black, non-Hispanic $(n=45)$ & $75.6 \%$ & & $24.4 \%$ & & \\
\hline White, non-Hispanic $(n=35)$ & $68.6 \%$ & & $31.4 \%$ & & \\
\hline Hispanic $(n=86)$ & $65.1 \%$ & & $34.9 \%$ & & \\
\hline Insurance status & & & & & 0.08 \\
\hline Uninsured (self-pay) $(n=18)$ & $77.8 \%$ & & $22.2 \%$ & & \\
\hline Public insurance $(n=85)$ & $60.0 \%$ & & $40.0 \%$ & & \\
\hline Private insurance $(n=80)$ & $75.0 \%$ & & $25.0 \%$ & & \\
\hline \multicolumn{6}{|l|}{ Area-based characteristics } \\
\hline Average household age (years) & 38.3 & 0.8 & 39.2 & 1.2 & 0.54 \\
\hline Percentage of white population & 60.9 & 1.4 & 55.5 & 2.3 & 0.40 \\
\hline Percentage of married couples & 63.9 & 1.0 & 64.4 & 1.5 & 0.78 \\
\hline Median household income (\$) & 34867 & 926 & 35247 & 1455 & 0.82 \\
\hline Percentage of families receiving public assistance & 7.5 & 0.3 & 7.4 & 0.5 & 0.94 \\
\hline Median real estate taxes (\$) & 1803 & 77 & 1885 & 106 & 0.55 \\
\hline Percentage of owner occupied houses & 56.7 & 1.4 & 55.5 & 2.3 & 0.64 \\
\hline
\end{tabular}

record review. Of the 175 patients whose medical records indicated that they were not guideline compliant, $30 \%$ $(\mathrm{n}=53)$ completed a telephone interview $(\mathrm{n}=45)$ or returned a mailed questionnaire $(n=8)$. Seventy percent $(37 / 53)$ of these patients indicated that they had received follow-up care every 15 months from other providers and were reclassified as compliant. Since we were unable to reach 122 of the potentially noncompliant patients, we compared the patient-level and area-based census characteristics of those who did and did not complete either a telephone or mail survey and found no statistically significant differences between groups (results not shown).

Neither patient characteristics nor neighborhood socioeconomic measures were significantly associated with compliance (table 2). Those living eight or more miles from the eye care facility were not significantly different from those living within eight miles in being compliant with dilated eye examinations (models 1-3; table 3). However, in model 4, which adjusted for age, sex, insurance status, median neighborhood household

Table 3 Distance to screening facility and odds of compliance following adjustment for spatial, individual-level, and neighborhood-level characteristics

\begin{tabular}{|c|c|c|c|c|c|c|c|c|}
\hline & \multicolumn{2}{|c|}{$\begin{array}{l}\text { Model } 1 \\
\text { Univariate } \\
(n=195)\end{array}$} & \multicolumn{2}{|c|}{$\begin{array}{l}\text { Model } 2 \\
\text { Autocovariate } \\
\text { adjusted }(n=195)\end{array}$} & \multicolumn{2}{|c|}{$\begin{array}{l}\text { Model } 3 \\
\text { Autocovariate } \\
\text { and individual } \\
\text { factor adjusted } \\
(n=193)\end{array}$} & \multicolumn{2}{|c|}{$\begin{array}{l}\text { Model } 4 \\
\text { Autocovariate, } \\
\text { individual factor, } \\
\text { and } \\
\text { neighborhood } \\
\text { adjusted }(n=192)\end{array}$} \\
\hline & OR & $95 \% \mathrm{Cl}$ & OR & $95 \% \mathrm{Cl}$ & OR & $95 \% \mathrm{Cl}$ & OR & $95 \% \mathrm{Cl}$ \\
\hline $\begin{array}{l}\text { Distance to facility ( }<8 \text { miles=reference } \\
\text { vs } \geq 8 \text { miles) }\end{array}$ & 0.64 & 0.35 to 1.18 & 0.55 & 0.29 to 1.06 & 0.52 & 0.27 to 1.01 & $0.36^{*}$ & 0.14 to 0.86 \\
\hline Age (<45 years (reference) vs $45+)$ & & & & & 0.63 & 0.32 to 1.26 & 0.67 & 0.33 to 1.37 \\
\hline Sex (male=reference vs female) & & & & & 0.82 & 0.43 to 1.53 & 0.86 & 0.45 to 1.62 \\
\hline Insurance (yes=reference vs no) & & & & & 0.61 & 0.26 to 1.42 & 0.70 & 0.30 to 1.66 \\
\hline $\begin{array}{l}\text { Percentage of white population in the } \\
\text { neighborhood }\end{array}$ & & & & & & & 1.00 & 0.99 to 1.02 \\
\hline $\begin{array}{l}\text { Median household income in the } \\
\text { neighborhood }\end{array}$ & & & & & & & 1.00 & 1.00 to 1.00 \\
\hline
\end{tabular}

${ }^{*} \mathrm{p}<0.05$. 
Table 4 Quality of access to public transportation and odds of compliance following adjustment for spatial, individual-level, and neighborhood-level characteristics

\begin{tabular}{|c|c|c|c|c|c|c|c|c|}
\hline & \multicolumn{2}{|c|}{$\begin{array}{l}\text { Model } 1 \\
\text { Univariate } \\
(n=195)\end{array}$} & \multicolumn{2}{|c|}{$\begin{array}{l}\text { Model } 2 \\
\text { Autocovariate } \\
\text { adjusted }(n=195)\end{array}$} & \multicolumn{2}{|c|}{$\begin{array}{l}\text { Model } 3 \\
\text { Autocovariate } \\
\text { and individual } \\
\text { factor adjusted } \\
(n=193)\end{array}$} & \multicolumn{2}{|c|}{$\begin{array}{l}\text { Model } 4 \\
\text { Autocovariate, } \\
\text { individual factor, } \\
\text { and } \\
\text { neighborhood } \\
\text { adjusted }(n=192)\end{array}$} \\
\hline & $\overline{\text { OR }}$ & $95 \% \mathrm{Cl}$ & $\overline{\text { OR }}$ & $95 \% \mathrm{Cl}$ & $\overline{\text { OR }}$ & $95 \% \mathrm{Cl}$ & $\overline{\text { OR }}$ & $95 \% \mathrm{Cl}$ \\
\hline Transit score & 1.19 & 1.00 to 1.43 & $1.25^{\star}$ & 1.05 to 1.50 & $1.24^{*}$ & 1.04 to 1.50 & $1.34^{*}$ & 1.07 to 1.68 \\
\hline Age $(<45$ years (reference) vs $45+$ ) & & & & & 0.68 & 0.34 to 1.37 & 0.71 & 0.34 to 1.50 \\
\hline Sex (male=reference) & & & & & 0.90 & 0.48 to 1.70 & 0.99 & 0.52 to 1.88 \\
\hline Insurance (yes=reference vs no) & & & & & 0.62 & 0.25 to 1.47 & 0.72 & 0.29 to 1.76 \\
\hline $\begin{array}{l}\text { Percentage of white population in the } \\
\text { neighborhood }\end{array}$ & & & & & & & 1.01 & 0.99 to 1.02 \\
\hline $\begin{array}{l}\text { Median household income in the } \\
\text { neighborhood }\end{array}$ & & & & & & & 1.00 & 0.99 to 1.00 \\
\hline
\end{tabular}

income, racial neighborhood composition, and spatial autocorrelation, living more than eight or more miles from the eye care facility was associated with a lower odds of compliance $(\mathrm{OR}=0.36$ (95\% CI 0.14 to 0.86$)$ ). Transit score also showed a significant association with the probability of compliance in models 2-4 (table 4). In the fully adjusted model 4 , the OR was 1.34 (1.07 to 1.68), indicating that after covariate adjustment the compliance rate increases by $34 \%$ with a 1-unit (or 10\%) increase in the transit score.

\section{DISCUSSION}

We found that all examined patient-level and neighborhood-level census measures failed to distinguish between patients with diabetes diagnosis who did and did not have dilated eye examinations at least every 15 months during the 24-36-month study period. However, after adjusting for demographics, those living more than eight miles from the eye care facility were less likely to be compliant. We also found that the quality of access to public transportation was strongly associated with compliance. We do not believe that an association between the quality of public transportation access and dilated eye examination compliance has ever been reported in the scientific literature. Both distance to the eye care facility and transit score are highly correlated $(\mathrm{r}=0.72, \mathrm{p}<0.001)$, which precluded modeling both simultaneously. However, of the two measures, we believe that the findings for transit score, which captures the ease with which a person can return for repeat eye examinations, especially individuals who do not have motor vehicle access, have the most implications for improving compliance in urban settings. This is especially relevant for interpretation of results since the eye care facility is contracted to provide ophthalmic care for county residents lacking healthcare access.
Our findings suggest that transportation access is one barrier that could be addressed through interventions designed to lower such barriers via travel vouchers and arranging for transportation to eye care facilities. However, even the provision of free transportation may not mitigate these low compliance rates, especially in economically distressed communities. For example, in one comprehensive community-based eye disease screening program, those who tested positive and needed follow-up care were offered free transportation to the clinic site. Despite this offer, only about $50 \%$ of those who agreed to the follow-up examination completed the visit. ${ }^{23}$

Thus, unless they are paired with interventions designed to increase compliance with eye care guidelines, interventions focused solely on lowering transportation barriers may not substantially improve compliance rates. A randomized trial testing an educational intervention targeting African-Americans with diabetes but with no dilated eye examination in the previous 14 months yielded a significantly higher subsequent examination rate in those in the intervention versus usual care arms of the trial $(55 \%$ vs $27 \%) .{ }^{24}$ In a recent analysis of data from the Behavioral Risk Factor Surveillance System, participants 40 years of age or older with a self-reported diagnosis of diabetes were significantly more likely to report seeing an eye care provider in the previous 12 months if they also indicated a history of receiving diabetes education $\left(57 \%\right.$ vs $43 \%$, p<0.001) ${ }^{25}$ Although speculative, these findings raise the possibility that those living with diabetes may be more responsive to transportation interventions if they also receive education on the importance of routine eye examinations.

Alternately, results of the present analysis suggest that dispersed eye care access throughout communities could be more effective in increasing dilated eye examination compliance rates. ${ }^{23}$ Such screening efforts could specifically target communities with poor transportation access, 
and could include ongoing efforts to educate those living with diabetes on the importance of regular eye examinations. However, the challenges of increasing compliance rates, particularly in underserved communities, cannot be overemphasized. ${ }^{26}$ For example, one previous intervention targeting low-income urban diabetic adults who had not had a recent eye examination found that telephone prompts led to an increased 6-month dilated eye examination rate over those randomized to receive mailed prompts. However, rates for both groups remained suboptimal: $34 \%$ vs $20 \% .{ }^{11}$ Embedding a telemedicine screening program within a federally qualified health center targeting the medically underserved nearly doubled the proportion of diabetic patients who were screening compliant; however, the overall percentage of compliant patients was still below 25\%. ${ }^{27}$ Our findings, combined with the aforementioned modest intervention results, raise the possibility that in order to substantially increase dilated eye examination rates in the medically underserved urban populations, it may be necessary to combine direct marketing of eye care opportunities, such as tailored phone interventions and intensive community engagement, for the purposes of educating target populations on the need for regular eye examinations. This approach could be combined with eye care modalities delivered via mobile examination units sent directly to patient addresses or to nearby community centers. There has been some success in the use of community health workers to facilitate screening compliance and follow-up rates targeting other conditions ${ }^{28-31}$; therefore, programs with high visibility, ease of access, and embedded within integrative chronic care models may gradually reduce the number of persons with diabetes who do not undergo annual eye examinations, while simultaneously improving overall diabetes care management. ${ }^{28-31}$

\section{Study limitations}

Our study was limited by the incomplete follow-up of those judged to be noncompliant based on a medical record review. We had only limited success in reaching these patients by phone or mail. Therefore, our compliance rate of $31 \%$ is most likely an underestimate of the true rate. This misclassification may have also influenced our ability to accurately identify predictors of compliance. Our relatively small sample size, combined with lack of information in the medical record, prevented us from examining the role of language barriers in compliance rates. Finally, this study took place in an urban setting, so results may not generalize to those living in suburban and rural settings.

\section{CONCLUSIONS}

Less than one-third of patients in our study were compliant with dilated eye examination guidelines. Compliance was associated only with living within eight miles from the eye care facility and more strongly with quality of access to public transportation in the urban setting in which this study took place. Study results reinforce the notion that the current environment for routinely meeting dilated eye examination guidelines is far from adequate, and new models which seamlessly embed eye care and educational opportunities within communities, with robust mechanisms for follow-up care for those who test positive, need to be developed and tested.

\section{Author affiliations}

${ }^{1}$ Department of Public Health Sciences, University of Miami Miller School of Medicine, Miami, Florida, USA

${ }^{2}$ Department of Ophthalmology, University of Miami Miller School of Medicine, Miami, Florida, USA

${ }^{3}$ Division of Diabetes Translation, National Center for Chronic Disease Prevention and Health Promotion, Centers for Disease Control and Prevention, Atlanta, USA

Contributors DJL and BLL helped to plan the study, draft/review/edit the manuscript, and secured project funding. NK, WJF, and JCS contributed to data analysis and interpretation and reviewed/edited the manuscript. PRR, AA, and PS assisted with data abstraction and collection and reviewed/edited the manuscript. C-FC, CAF, and SLT assisted with protocol development and helped draft/review/edit the manuscript.

Funding This research was supported by the Centers for Disease Control and Prevention (5U58DP002651, 1U58DP002652, 5U58DP002653,

1U58DP002655). Grantees include the University of Alabama at Birmingham, Johns Hopkins University, Wills Eye Hospital, and the University of Miami. Additional support was provided by an NIH Center Core Grant P30EY014801, a Research to Prevent Blindness Unrestricted Grant, and a Department of Defense grant (DOD-Grant\#W81XWH-09-1-0675).

\section{Competing interests None.}

Ethics approval The University of Miami Institutional Review Board approved this study (protocol \# 20100858).

Provenance and peer review Not commissioned; externally peer reviewed.

Data sharing statement No additional data are available.

Open Access This is an Open Access article distributed in accordance with the Creative Commons Attribution Non Commercial (CC BY-NC 4.0) license, which permits others to distribute, remix, adapt, build upon this work noncommercially, and license their derivative works on different terms, provided the original work is properly cited and the use is non-commercial. See: http:// creativecommons.org/licenses/by-nc/4.0/

\section{REFERENCES}

1. Cheng YJ, Imperatore G, Geiss LS, et al. Secular changes in the age-specific prevalence of diabetes among US adults: 1988-2010. Diabetes Care 2013;36:2690-6.

2. 2011 National Diabetes Fact Sheet. Centers for Disease Control and Prevention. http://www.cdc.gov/diabetes/pubs/estimates11.htm (accessed 21 Jan 2014).

3. Antonetti DA, Klein R, Gardner TW. Diabetic retinopathy. N Engl J Med 2012;366:1227-39.

4. CDC. Improving the nation's vision health: a coordoinated public health approach. Atlanta: Centers for Disease Control and Prevention. http://www.cdc.gov/visionhealth/pdf/improving_nations_ vision_health.pdf (accessed 16 Nov 2009).

5. Saaddine JB, Honeycutt AA, Narayan KM, et al. Projection of diabetic retinopathy and other major eye diseases among people with diabetes mellitus: United States, 2005-2050. Arch Ophthalmol 2008;126:1740-7.

6. Bragge P, Gruen RL, Chau M, et al. Screening for presence or absence of diabetic retinopathy: a meta-analysis. Arch Ophthalmol 2011;129:435-44.

7. American Academy of Ophthalmology Preferred Practice Pattern Guidelines- Diabetic Retinopathy PPP_Updated October 2012. http://one.aao.org/CE/PracticeGuidelines/PPP Content.aspx? $\mathrm{cid}=\mathrm{d} 0 \mathrm{c} 853 \mathrm{~d} 3-219 \mathrm{f}-487 \mathrm{~b}-\mathrm{a} 524-326 \mathrm{ab3cecd} 9 \mathrm{a}$ \#section3 (accessed 18 Sep 2013) 
8. American Diabetes Association. Standards of medical care in diabetes-2013. Diabetes Care 2013;36(Suppl 1):S11-66.

9. Shaw SJ, Huebner C, Armin J, et al. The role of culture in health literacy and chronic disease screening and management. $J$ Immigr Minor Health 2009;11:460-7.

10. Zhang X, Norris SL, Saadine J, et al. Effectiveness of interventions to promote screening for diabetic retinopathy. Am J Prev Med 2007;33:318-35.

11. Walker EA, Schechter CB, Caban A, et al. Telephone intervention to promote diabetic retinopathy screening among the urban poor. $A m \mathrm{~J}$ Prev Med 2008;34:185-91.

12. Lee SJ, McCarty CA, Sicari C, et al. Recruitment methods for community-based screening for diabetic retinopathy. Ophthalmic Epidemiol 2000;7:209-18.

13. Lee PP, Feldman ZW, Ostermann J, et al. Longitudinal rates of annual eye examinations of persons with diabetes and chronic eye diseases. Ophthalmology 2003;110:1952-9.

14. Mukamel DB, Bresnick GH, Wang Q, et al. Barriers to compliance with screening guidelines for diabetic retinopathy. Ophthalmic Epidemiol 1999;6:61-72.

15. Saadine JB, Fong DS, Yao J. Factors associated with follow-up eye examinations among persons with diabetes. Retina 2008;28:195-200.

16. Peipins LA, Graham S, Young R, et al. Time and distance barriers to mammography facilities in the Atlanta metropolitan area. $J$ Community Health 2011;36:675-83.

17. Kumar N. Changing geographic access to and locational efficiency of health services in two Indian districts between 1981 and 1996. Soc Sci Med 2004:58:2045-67.

18. Zenk SN, Tarlov E, Sun J. Spatial equity in facilities providing low- or no-fee screening mammography in Chicago neighborhoods. J Urban Health 2006:83:195-210.

19. US Census Bureau. Geographic Terms and Concepts. 2013. http://www. census.gov/geo/reference/gtc/gtc ct.html (accessed 20 Sep 2013).

20. Gilmour D, Blackwood D, Banks L, et al. Sustainable development indicators for major infrastructure projects. P I Civil Eng Munic 2011;164:15-24.
21. R Development Core Team. R: A language and environment for statistical computing. 2012. http://www.R-project.org

22. Fischer JM, Amekudzi A. Quality of life, sustainable civil infrastructure, and sustainable development: strategically expanding choice. J Urban Plan D Asce 2011;137:39-48.

23. Quigley HA, Park CK, Tracey PA, et al. Community screening for eye disease by laypersons: the Hoffberger program. $A m \mathrm{~J}$ Ophthalmol 2002;133:386-92.

24. Basch CE, Walker EA, Howard CJ, et al. The effect of health education on the rate of ophthalmic examinations among African Americans with diabetes mellitus. Am J Public Health 1999;89:1878-82.

25. Chou CF, Sherrod C, Zhang X, et al. Barriers to eye care among people aged 40 years and older with diagnosed diabetes, 20062010. Diabetes Care 2014;37:180-8.

26. Hazin R, Barazi MK, Summerfield M. Challenges to establishing nationwide diabetic retinopathy screening programs. Curr Opin Ophthalmol 2011;22:174-9.

27. Olayiwola JN, Sobieraj DM, Kulowski K, et al. Improving diabetic retinopathy screening through a statewide telemedicine program at a large federally qualified health center. $J$ Health Care Poor Underserved 2011;22:804-16.

28. Braun KL, Kagawa-Singer M, Holden AE, et al. Cancer patient navigator tasks across the cancer care continuum. $J$ Health Care Poor Underserved 2012;23:398-413.

29. Hunt CW, Grant JS, Appel SJ. An integrative review of community health advisors in type 2 diabetes. $J$ Community Health 2011;36:883-93.

30. Plumb J, Weinstein LC, Brawer R, et al. Community-based partnerships for improving chronic disease management. Prim Care 2012;39:433-47.

31. Cherrington A, Ayala GX, Amick $\mathrm{H}$, et al. Applying the community health worker model to diabetes management: using mixed methods to assess implementation and effectiveness. $J$ Health Care Poor Underserved 2008;19:1044-59. 